\title{
Jerat Hutang Luar Negeri Pemerintah dan BUMN Indonesia
}

\author{
Nur Feriyanto
}

Incapability of the Indonesian government to provide sufficient fund for the development process of the country, forces it to get financial support from foreign debts. Statistical figures indicate that for many decades, the amount of the foreign debts raises dramatically. As a result, the country then is trapped in the very deep foreign debts in which the country is. very difficult to escape.

\section{Pengantar}

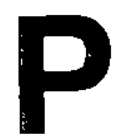

embangunan ekonomi yang dilakukan negara berkembang sering menimbulkan problem besar dalam pendanaannya. Keinginan yang besar untuk memacu pembangunan nasional untuk mengejar ketertinggalan pembangunan nasional dari negara lain seringkali terbentur tembok kuat adanya keterbatasan dalam pembentukan modal, baik dari penerimaan pemerintah ataupun tabungan masyarakat. Rendahnya penerimaan negara disebabkan rendahnya ekspor dan pajak sedangkan lemahnya kemampuan tabungan masyarakat bersumber pada rendahnya penerimaan masyarakat.

Problem di atas juga menimpa Indonesia yang berusaha keras mendorong pembangunan nasional untuk mengejar ketertinggalannya dari negara-negara lain. Pajak yang seharusnya menjadi andalan penerimaan negara masih banyak mengalami kendala karena belum dimilikinya sistem administrasi yang efisien dan struktur pajak yang adil. Akibatnya, upaya keras pemerintah Indonesia menggenjot pajak melalui intensifikasi dan ekstensikasi pajak seringkali kontra-produktif karena melemahkan sektor riil.

Ekspor migas dan nonmigas Indonesia sebagai alternatif penerimaan negara dalam perkembangannya terbukti juga belum dapat sepenuhnya menutup kebutuhan pendanaan pembangunan Indonesia mengingat fluktuasi perdagangan global masih tinggi dan daya saing produkproduk nasional belum cukup kuat untuk bersaing secara global. Menyadari bahwa pembangunan nasional harus tetap jalan meskipun kemampuan penerimaan domestik belum mencukupi maka pemerintah melakukan hutang luar negeri.

Hutang luar negeri oleh Pemerintah dan BUMN Indonesia telah dilakukan selama tiga dekade yaitu sejak tahun 1969 . 
Besarnya potensi sumberdaya alam yang dimiliki Indonesia menjadikan permintaan hutang Pemerintah dan BUMN Indonesia ke pihak donor luar negeri (baik secara bilateral atau multilateral) hampir tidak ada hambatan. Aliran masuk hutang luar negeri terasa manfaatnya pada saat awal pembangunan nasional dilaksanakan.

Kebiasaan dan mudahnya berhutang ternyata kurang bermanfaat dalam perkembangan perilaku birokrat di Indonesia. Hal itu terjadi karena semakin melemahnya kendali mereka terhadap kualitas dan pemanfaatan proyek-proyek pembangunan nasional. Kurangnya kontrol DPR terhadap penggunaan dana pembangunan dari hutang luar negeri telah menyebabkan hutang luar negeri Pemerintah dan BUMN Indonesia menjadi kurang efektif dalam menunjang tujuan utama dilakukan hutang luar negeri tersebut dan memperberat problem diseputar hutang luar negeri Indonesia. Akibatnya, hutang luar negeri Pemerintah dan BUMN Indonesia dari tahun ketahun terus membengkak dan karena penggunaan hutang tersebut tidak optimal (kurang berdayaguna) maka akhirnya berimplikasi pada melemahnya kemampuan Pemerintah dan BUMN Indonesia dalam membayar angsuran hutang luar negerinya.

Tulisan ini memfokuskan pada hutang luar negeri Pemerintah dan BUMN Indonesia, pengeluaran pembangunan, belanja pegawai serta angsuran hutang luar negeri berupa pokok pinjaman dan bunganya. Penggunaan periode penelitian dari tahun 1980-1999 diharapkan dapat menggambarkan perilaku variabel-variabel di atas.

\section{Tinjauan Teori}

Hambatan besar dalam pembangunan ekonomi negara terbelakang hanya dapat tertanggulangi melalui "dorongan kuat" berupa investasi. Teori yang dikemukakan oleh Prof Paul N. Rosenstein-Rodan ini dikenal dengan Big Push Theory.

Ada sejumlah sumber minimum yang harus disediakan oleh suatu negara jika suatu program pembangunan diharapkan berhasil. Agar diperoleh keberhasilan ekonomi suatu negara maka jumlah investasi minimum itu harus dapat mendorong secara kuat (big push) gerak pembangunan ekonomi di negara tersebut.

Teori itu menyatakan bahwa suatu jumlah minimum investasi merupakan syarat mutlak untuk dapat melewati lintasan pembangunan dan melewati titik kritisnya. Negara membutuhkan industri-industri yang secara teknik dan ekonomis saling berkaitan, sehingga gerak pembangunan ekonomi dapat terbangun secara baik, terkait dan berkesinambungan. Untuk itu diperlukan sejumlah minimum investasi agar industri-industri yang dibutuhkan tersebut dapat berdiri.

Rosenstein-Rodan memberikan 3 macam syarat mutlak minimal. Pertama, syarat mutlak minimal dalam fungsi produksi, khususnya syarat mutlak minimal pada persediaan modal overhead sosial. Jumlah investasi minimal dalam input, output atau proses mengakibatkan peningkatan penghasilan Kedua, syarat mutlak minimal pada permintaan. Investasi pada industriindustri harus terkait dan dapat menciptakan permintaannya. Ketiga, syarat mutlak minimal dalam persediaan tabungan. (Jhingan, 1988)

Pemikiran lain dikemukan oleh Nurkse dengan istilah the vicious circle (lingkaran setan). Nurkse menjelaskan istilah lingkaran setan sebagai deretan melingkar kekuatankekuatan yang satu sama lain berreaksi sedemikian rupa sehingga menempatkan suatu negara miskin tetap berada dalam keadaan melarat. Lingkaran setan pada pokoknya berasal dari fakta bahwa 
produktivitas total di negara terbelakang sangat rendah sebagai akibat kekurangan modal, pasar yang tidak sempurna, dan keterbelakangan perekonomian. Lingkaran setan tersebut kalau dilihat dari sudut permintaan dapat dijelaskan sebagai berikut: rendahnya tingkat pendapatan nyata menyebabkan tingkat permintaan menjadi rendah, sehingga pada gilirannya tingkat investasi pun rendah. Tingkat investasi yang rendah kembali menyebabkan modal kurang dan produktivitas rendah. Produktivitas rendah tercermin di dalam pendapatan nyata yang rendah. Pendapatan nyata rendah berarti tingkat tabungan juga rendah. Tingkat tabungan yang rendah menyebabkan tingkat investasi rendah dan modal kurang. Kekurangan modal pada gilirannya bermuara pada produktivitas yang rendah. Tingkat pendapatan rendah yang mencerminkan rendahnya investasi dan kurangnya modal, merupakan ciri umum kedua lingkaran setan tersebut. Lingkaran setan yang ketiga menyangkut keterbelakangan manusia dan sumber alam. (Jhingan, 1988)

Fenomena ketidakmampuan negara pengambil hutang dalam membayar kewajibannya (pokok pinjaman dan bunganya) digambarkan oleh Profesor Fisher dengan istilah Fisher Paradox. Pengertian Fisher Paradox ini dikemukan oleh Fisher sebagai berikut:

"Each dollar of debt still unpaid becomes bigger dollar and if the over indebtedness with which we started was great enough, the liquidation of debt cannot keep up with the fall of prices, which it causes. In that case, the liquidation defeats itself. While it diminished the number of dollar owed, it may not do so as fast as it increases the value of each dollar owed. Then, the very effort of individuals to lessen their burden of debts increases it... The we have the graet paradox: The more the debtors pay, the more they owe" (Fisher, 1993).

Fisher paradoxmengemukakan bahwa negara-negara penghutang besar terpaksa melakukan net transfer dan berbarengan dengan itu mengalami kemerosotan dalam daya beli penghasilan ekspornya, jelas mengalami situasi yang menunjukkan bahwa semakin besar nilai pembayaran cicilan pokok hutang luar negeri, semakin besar nilai hutang luar negera ini, semakin besar nilai hutang luar negeri yang menumpuk (Sritua Arief, 1999).

\section{Gambaran Umum Hutang Luar Negeri Indonesia}

Secara umum posisi hutang luar negeri Indonesia dari tahun 1996-2001 yang terdiri dari hutang pemerintah dan swasta menunjukkan kecenderungan naik dari tahun 1996-1998 dan mulai menurun pada tahun 1999. Jumlah total hutang luar negeri Indonesia tahun 1996 sebesar 110.171 juta dollar AS dan mencapai nilai tertinggi pada tahun 1998 yaitu sebesar 150.887 juta dollar AS. Tetapi mulai tahun 1999 menurun menjadi 148.097 juta dollar AS dan sampai bulan Agustus 2001 menurut data Bank Indonesia jumlah hutang luar negeri Indonesia berjumlah 137.603 juta dollar AS. Dari hutang luar negeri tersebut hutang Pemerintah sebesar 74.164 juta dollar AS merupakan bagian terbesar dari hutang luar negeri Indonesia $(54 \%)$ dan swasta sebesar 63.438 juta dollar AS (46\%).

Perkembangan hutang luar negeri pemerintah dari tahun 1996-1999 terlihat cenderung meningkat dan mulai menurun dari tahun 2000. Penurunan ini tentunya terkait dengan beban tinggi yang harus dipikul pemerintah dalam melakukan 
kewajiban membayar angsuran hutang luar negeri yang terdiri dari pokok pinjaman dan bunganya. Menurut data PERC (Pacific Economin Risk Consultancy) cicilan hutang luar negeri Indonesia sebesar 21,82 milyar dolar AS tahun 1999 dan tahun 2000 sebesar 21,79 milyar dolar AS. (Kompas 16 April 2001)

Hutang luar negeri swasta Indonesia menunjukkan kenaikan tajam, karena pada tahun 1996 hutang luar negeri swasta "baru"sebesar 54.868 juta dollar AS tetapi tahun 1997 menjadi 82.223 juta dolar AS dan naik lagi menjadi 83.572 juta dollar AS pada tahun 1998. Kecenderungan penurunan hutang luar negeri swasta terlihat terjadi mulai tahun 1999. Hutang luar negeri swasta tersebut terdiri dari pinjaman bank, non bank dan surat berharga (tabel 1).

Tabel 1

Pos Pinjaman Luar Negeri Indonesia (juta dollar AS)

\begin{tabular}{|c|c|c|c|c|c|c|}
\hline & 1996 & 1997 & 1998 & 1999 & 2000 & $2001^{*}$ \\
\hline Pemerintah & 55.303 & 53.865 & 67.315 & 75.862 & 74.961 & 74.164 \\
\hline Swasta: & 54.868 & 82.223 & 83.572 & 72.235 & 66.769 & 63.438 \\
\hline 1) Bank & 9.049 & 14.364 & 14.364 & 10.836 & 7.719 & 6.952 \\
\hline 2) Non Bank & 45.819 & 57.588 & 57.588 & 58.243 & 56.879 & 54.429 \\
\hline 3) Surat Berharga & - & 10.271 & 5.288 & 3.156 & 2.171 & 2.056 \\
\hline Total & 110.171 & 136.088 & 150.887 & 148.097 & 141.685 & 137.602 \\
\hline
\end{tabular}

Sumber: Bank Indonesia sebagaimana dikutip Kompas, 8 Oktober 2001

Catatan: tahun 2001 sampai Agustus

Data yang digunakan dalam penelitian adalah data sekunder runtut waktu mulai tahun 1980 sampai dengan tahun 1999 bersumber dari Nota Keuangan dan APBN 1996/1997, 1999/2000 dan 2000 serta Laporan Tahunan Bank Indonesia 2000.

Metode penelitian yang digunakan dalam penelitian adalah metode diskriptif dan ekonometrika. Metode diskriptif digunakan untuk menggambarkan perkembangan variabel-variabel penelitian sehingga dapat diketahui tingkat dan pola pertumbuhan selama periode penelitian dilakukan. Metode ekonometrika dipakai untuk menguji pengaruh pengeluaran pembangunan, belanja pegawai dan pembayaran pokok pinjaman dan bunga hutang terhadap hutang luar negeri pemerintah dan BUMN.

- Variabel dependen adalah Hutang Pemerintah dan BUMN Indonesia (UPB) yaitu jumlah keseluruhan hutang yang dimiliki pemerintah dan BUMN Indonesia dalam satuan juta dolar AS.

- Variabel independent meliputi:

Pengeluaran Pembangunan (PP) adalah jumlah pengeluaran pembangunan nasional dalam satuan Milyar-Rupiah.

Belanja Pegawai (BP) adalah jumiah pengeluaran untuk belanja pegawai dalam satuan Milyar Rupiah. 
Pokok Pinjaman dan Bunga Hutang (PBH) adalah jumlah pengeluaran untuk membayar pokok pinjaman dan bunga hutang Pemerintah dan BUMN dalam satuan juta dolar AS.

Model yang digunakan dalam penelitian ini adalah model OLS (Ordinary Least Square) non linier: $L U P B=\alpha 0+\alpha 1 L P P+\alpha 2 \mathrm{LBP}+$ $\alpha 3$ LPBH.

\section{Hutang Pemerintah $=$ Hutang BUMN}

Jumlah hutang luar negeri Pemerintah dan BUMN dari tahun 1980-1999 menunjukkan peningkatan yang sangat berarti tetapi dengan tingkat pertumbuhan yang berbeda. Hutang luar negeri Pemerintah baik secara absolut ataupun tingkat pertumbuhan pertahun lebih tinggi dibandingkan BUMN Indonesia. Selama tahun 1980-1999 ratarata pertumbuhan hutang luar negeri Pemerintah Indonesia menunjukkan angka $14,31 \%$, sedangkan BUMN Indonesia mencapai $6,65 \%$. Pada tahun 1980 hutang Pemerintah Indonesia baru sebesar 12.994 juta dollar AS tetapi pada tahun 1999 nilai hutang luar negerinya sudah berlipat mencapai 68.689 juta dollar AS. Berarti selama 20 tahun hutang luar negeri Pemerintah Indonesia telah terjadi kelipatan sebesar 5,29 kali.

Hutang luar negeri BUMN Indonesia menujukkan bahwa tahun 1980 masih berjumlah 1.876 juta dollar $A S$, tetapi pada tahun 1999 telah meningkat menjadi 5.067 juta dollar AS. Melihat angka tersebut maka dapat disimpulkan bahwa dari tahun 19801999 hutang luar negeri tersebut telah meningkat 2,7 kalinya. (tabel 2)

Fakta-fakta tersebut di atas menggambarkan bagaimana Pemerintah dan BUMN Indonesia seakan berlomba untuk mencari hutang luar negeri sebesar-besarnya. Hal ini juga menunjukkan kegagalan Pemerintah dan BUMN Indonesia dalam menghimpun tabungan domestik bagi pemenuhan kebutuhannya. Ketergantungan pada hutang luar negeri yang begitu besar menjadikan kemandirian ekonomi dan politik Pemerintah dan BUMN Indonesia semakin lemah. 
Topik: Jerat Hutang Luar Negeri Pemerintah dan BUMN Indonesia, Nur..Feriyanto

Tabel 2

Hutang Luar Negeri Pemerintah dan BUMN Indonesia

\begin{tabular}{|c|c|c|c|c|c|c|}
\hline \multirow[t]{2}{*}{ Tahun } & \multicolumn{2}{|c|}{ Tahun } & \multicolumn{2}{|c|}{ BUMN } & \multicolumn{2}{|c|}{ Total } \\
\hline & Juta \$ AS & $\begin{array}{l}\text { Pèrtumb } \\
(\%)\end{array}$ & Juta \$ AS & $\begin{array}{l}\text { Pertumb } \\
(\%)\end{array}$ & Juta \$ AS & $\begin{array}{c}\text { Pertumb } \\
(\%)\end{array}$ \\
\hline $\begin{array}{l}1980 \\
1981 \\
1982 \\
1983 \\
1984 \\
1985 \\
1986 \\
1987 \\
1988 \\
1989 \\
1990 \\
1991 \\
1992 \\
1993 \\
1994 \\
1995 \\
1996 \\
1997 \\
1998 \\
1999 \\
\text { Pertumbuhan/th } \\
\text { Peningkatan hutang } \\
\text { dari 1980-1999 }\end{array}$ & $\begin{array}{c}12.994 \\
13.945 \\
16.767 \\
19.953 \\
22.189 \\
25.321 \\
31.521 \\
38.417 \\
38.983 \\
39.577 \\
45.100 \\
45.725 \\
48.769 \\
52.462 \\
58.616 \\
59.588 \\
55.303 \\
53.865 \\
67.315 \\
68.689 \\
- \\
5,29 \text { kali }\end{array}$ & $\begin{array}{r}7,32 \\
20,2 \\
19,0 \\
11,2 \\
14,1 \\
24,5 \\
21,9 \\
1,50 \\
1,50 \\
14,0 \\
1,4 \\
6,70 \\
7,60 \\
11,7 \\
1,70 \\
-7,20 \\
-2,60 \\
25,0 \\
2,00 \\
14,31 \\
.\end{array}$ & $\begin{array}{r}1.876 \\
2.184 \\
3.270 \\
3.480 \\
3.320 \\
2.997 \\
3.073 \\
3.149 \\
3.277 \\
3.650 \\
4.257 \\
3.359 \\
4.516 \\
5.060 \\
5.070 \\
4.822 \\
3.742 \\
3.995 \\
4.153 \\
5.067 \\
- \\
2,70 \text { kali }\end{array}$ & $\begin{array}{r}- \\
16,40 \\
49,73 \\
6,42 \\
-4,60 \\
-9,7 \\
2,54 \\
2,47 \\
4,07 \\
11,38 \\
16,63 \\
-21,10 \\
34,44 \\
12,05 \\
0,20 \\
-4,89 \\
-22,40 \\
6,76 \\
3,96 \\
22,01 \\
6,65\end{array}$ & $\begin{array}{r}14.870 \\
16.129 \\
20.037 \\
23.433 \\
25.509 \\
28.318 \\
34.594 \\
41.566 \\
42.260 \\
43.227 \\
49.357 \\
49.084 \\
53.285 \\
57.522 \\
63.686 \\
64.410 \\
59.045 \\
57.860 \\
71.468 \\
73.756 \\
- \\
4.96 \text { kali }\end{array}$ & $\begin{array}{r}- \\
8,5 \\
24,2 \\
16,9 \\
8,9 \\
11 \\
22,2 \\
20,2 \\
1,7 \\
2,3 \\
14,2 \\
-0,5 \\
8,56 \\
7,95 \\
10,7 \\
1,14 \\
-8,3 \\
-2 \\
23,5 \\
3,2 \\
9,2\end{array}$ \\
\hline
\end{tabular}

Sumber: Bank Indonesia, 2000. diolah

Perkembangan pembayaran pokok pinjaman dan bunga hutang luar negeri Pemerintah dan BUMN dari tahun 19801999 sangat memprehatinkan. Akumulasi bunga hutang dari tahun 1980-1999 sebesar 48.356 juta dollar AS adalah $63,16 \%$ dari akumulasi pokok pinjaman atau $38,71 \%$ dari akumulasi pokok pinjaman dan bunganya. Total pokok pinjaman dan bunga meningkat tajam, dari tahun 1980 sebesar 1.762 juta dollar AS meningkat 4,6 kali pada tahun 1999. Hal ini mengindikasikan bahwa di lingkungan. Pemenintah dan BUMN Indonesia telah menjadi kebiasaan untuk terus berutang. (tabel 3). 
Tabel 3

Pokok Pinjaman dan Bunga Hutang Luar Negeri Pemerintah dan BUMN Indonesia

(dalam juta dolar AS)

\begin{tabular}{|l|l|l|r|}
\hline Tahun & \multicolumn{1}{|c|}{ Pinjaman Pokok } & \multicolumn{1}{c|}{ Bunga } & Total \\
\hline 1980 & 939 & 823 & 1.762 \\
1981 & 1.054 & 991 & 2.045 \\
1982 & 1.104 & 1.132 & 2.236 \\
1983 & 1.290 & 1.233 & 2.523 \\
1984 & 1.600 & 1.629 & 3.229 \\
1985 & 2.330 & 1.643 & 3.973 \\
1986 & 2.622 & 2.072 & 4.694 \\
1987 & 3.406 & 2.273 & 5.679 \\
1988 & 4.439 & 2.526 & 6.965 \\
1989 & 4.117 & 2.802 & 7.019 \\
1990 & 4.352 & 2.879 & 7.231 \\
1991 & 4.673 & 2.896 & 7.569 \\
1992 & 5.182 & 2.932 & 8.114 \\
1993 & 5.706 & 3.160 & 8.866 \\
1994 & 5.609 & 3.184 & 8.793 \\
1995 & 6.007 & 3.684 & 9.691 \\
1996 & 7.917 & 3.053 & 10.970 \\
1997 & 5.364 & 2.861 & 8.225 \\
1998 & 4.263 & 2.953 & 7.216 \\
1999 & 4.486 & 3.630 & 8.116 \\
Akumulasi & $76.560(61,29 \%$ dari & 48.356 (38,71\% dari & 124.916 \\
& total angsuran) & total angsuran) & \\
\hline
\end{tabular}

Sumber: Bank indonesia, 2000, diolah.

\section{Simpulan dan Implikasi Kebijakan}

Selama periode 1980-1999 hutang luar negeri Pemerintah dan BUMN Indonesia menunjukkan peningkatan yang pesat baik secara absolut ataupun persentase pertumbuhan pertahunnya. Pemerintah memiliki porsi yang lebih besar dibandingkan BUMN Indonsia dalam berutang ke luar negeri. Kecenderungan untuk terus berutang baik oleh Pemerintah maupun BUMN Indonesia menunjukkan lemah kemandirian ekonomi dan politiknya.

Pengeluaran pembangunan, belanja pegawai serta pembayaran pokok pinjaman dan bunganya secara serentak memiliki pengaruh yang signifikan terhadap hutang luar negeri Pemerintah dan BUMN Indonesia. Namun secara parsial hanya varabel belanja pegawai dan pembayar pokok pinjaman dan bunganya yang memiliki pengaruh signifikan positif terhadap hutang luar negeri Pemerintah dan BUMN Indonesia. Pengaruh paling dominan terhadap hutang luar negeri Pemerintah dan BUMN Indonesia adalah faktor pokok pinjaman dan bunganya. $\mathrm{Hal}$ ini mengindikasikan terjadinya jerat hutang luar negeri (debt trap) di Indonesia. 
Topik: Jerat Hutang Luar Negeri Pemerintah dan BUMN Indonesia, Nur Feriyanto

Implikasi kebijakan.yang dapat diambil adalah Pertama, strategi pembangunan industrialisasi Indonesia harus menekankan pada penggunaan faktor-faktor input produksi dalam negeri. Agar ketergantungan pada luar negeri dapat diminimalkan. Kedua, perlu upaya serius untuk mengurangi hutang luar negeri Pemerintah dan BUMN Indonesia melalui penjadwalan kembali dan pengurangan sisa hutang, agar kemandirian ekonomi politik dapat dimiliki Indonesia. Ketiga, efisiensi pada belanja pegawai harus dilakukan dengan memperbaiki administrasi kepegawaian nasional dan ketergantungan belanja pegawai sebagai bagian pengeluaran rutin terhadap hutang luar negeri harus mulai dikurangi.

\section{Daftar Pustaka}

Didik J Rachbini (2001), Ekonomi Politik Hutang, Ghalia Indonesia, Jakarta.

Fisher, (1993), The Debt Deflation Theory of Great Depressions, Econometrica 1.

Jhingan (1988), Ekonomi Pembangunan dan Perencanaan, Rajawali Pers, Jakarta.

Sritua Arief (1999). Hutang Luar Negeri dan Investasi Asing: Mitos \& Fakta, Wacana No III, 1999.

Kompas, 16 April 2001. , Hutang LN RI 137,6 Milyar Dollar AS, 8 Oktober 2001.

Bank Indonesia, Laporan Tahunan Bank Indonesia 2000.

Nota Keuangan dan APBN tahun 1996/ 1997, 1999/2000 dan 2000. 